\title{
Adenylate Cyclase Activity in Fetal Rabbit Myocardium
}

\author{
CHRISTOS G. HATJIS \\ Department of Obstetrics and Gynecology, Bowman Gray School of Medicine, Winston-Salem, \\ North Carolina 27103
}

\begin{abstract}
Adenylate cyclase activity [ATP pyrophosphate-lyase (cyclizing), EC 4.6.1.1] was determined in vitro in fetal rabbit myocardial membranes from individual fetal pups at 21 to 31 days gestation (term, 31 days). Basal and $\mathrm{NaF}$-stimulated adenylate cyclase activities did not change during 21-31 days gestation. Significant stimulation of the enzyme by $l$-isoproterenol was observed only in the presence of guanosine triphosphate $(100 \mu \mathrm{M})$. Under these conditions, maximal adenylate cyclase stimulation by $l$ isoproterenol $(100 \mu \mathrm{M})$ was significantly higher at 25-31 than at 21 days gestation. Moreover, $\mathrm{EC}_{50}\left(K_{\mathrm{act}}\right)$ for $l$ isoproterenol at 25-31 days was significantly lower than at 21 days gestation. We conclude that, in fetal rabbit myocardial membranes, there is an increase in the sensitivity of adenylate cyclase stimulation by $l$-isoproterenol from 21 to 25-31 days gestation (Pediatr Res 19: 75-78, 1985)
\end{abstract}

\section{Abbreviations}

\section{$\beta$-AR, $\beta$-adrenergic receptors}

HYP, hydroxybenzylpindolof

EGTA, ethylene glycol bis( $\beta$-aminoethyl ether)$N, N, N^{\prime}, N^{\prime}$-tetraacetic acid

The sympathetic nervous system is important in the control of heart rate and myocardial contractility (18). The stimulatory actions of catecholamines on cardiac tissue are primarily, but not exclusively, mediated via $\beta$-AR. These, in turn, regulate myocardial and heart rate responses to exogenous and endogenous stimuli through adenylate cyclase [ATP pyrophosphatelyase (cyclizing), EC 4.6.1.1]. This enzyme catalyzes the synthesis of $3^{\prime}, 5^{\prime}$-cyclic adenosine monophosphate, which acts as a second messenger $(17,26)$.

The interaction between the sympathetic nervous system and myocardial performance in fetuses and neonates has been extensively studied in several animal species (chick, rat, guinea pig, mouse, sheep, rabbit). Using well established in vivo and in vitro physiological and pharmacological methods, studies have suggested that there is a progressive increase in the ability of fetal myocardium to respond to exogenous and endogenous catecholamine stimuli with advancing gestation $(1,5,7,9,10,20,21$, 28, 29).

Potential causes for this improvement in myocardial perform-

Received November 4, 1983; accepted June 27, 1984

Requests for reprints should be addressed to C. G. Hatjis, M.D., Department of Obstetrics and Gynecology, Bowman Gray School of Medicine, 300 South Hawthorne Road. Winston-Salem, NC 27103.

This research was partially supported by United States Public Health Service Grant 5429-19-8, University of Vermont College of Medicine. ance could include a quantitative or qualitative change in one of the components of the $\beta$-adrenoreceptor/adenylate cyclase complex. With the advent of in vitro radioreceptor methodology and availability of sensitive enzymatic assays, it has become possible to study the molecular biology of this complex both in adult and fetal myocardia. We recently reported on the ontogenesis of $\beta$ adrenergic receptors in fetal rabbit myocardium using ${ }^{125} \mathrm{I}-\mathrm{HYP}$, a specific $\beta$-adrenergic receptor antagonist, as the radioligand. We found that there was a progressive increase in the density of $\beta$-adrenoreceptors with advancing gestation but no significant change in their affinity for ${ }^{125} \mathrm{I}-\mathrm{HYP}$ or unlabeled $\beta$-AR-specific agonists and antagonists (11). Similar results have been reported by other investigators in some animal species (5) but not in others $(2,6,33)$.

Adenylate cyclase activity in adult myocardial tissue has been studied in detail in several animal species $(6,8,13-15,23,24$, $27,30)$. However, there is significantly less information available about myocardial adenylate cyclase activity in fetal and neonatal animals. While some studies have suggested that there is a progressive increase in basal adenylate cyclase activity and per cent stimulation above baseline, others have not fully confirmed these results $(3,6,16,23,30)$. Recently, Schumacher and coworkers (23) reported on adenylate cyclase characteristics from pooled (not individual) 27-day gestation fetal, neonatal, and adult rabbit hearts and concluded that there was a progressive increase in the ability of the enzyme to respond maximally to high doses of $l$-isoproterenol from fetus and neonate to adult while the opposite was seen when half-maximal effective concentration of $l$-isoproterenol was determined. However, they did not indicate whether the latter change was statistically significant.

The present study was designed to examine the in utero adenylate cyclase activity in individual fetal rabbit hearts from 21 to 31 days gestation. We have asked the question whether enzymatic activity parallels the ontogenetic pattern seen in myocardial $\beta$-adrenergic receptor density in this species. Fetal rabbits were chosen for these studies for three reasons. First, observations can be initiated on individual animals while they are still in utero. Second, it has been shown that, in fetal rabbits, significant myocardial norepinephrine stores and sympathetic innervation do not appear until very late in gestation and in the early neonatal period (9). This could allow a developmental study of adenylate cyclase activity independent of external neuronal sympathetic input. Third, in order to clarify the question of species and gestational age differences regarding adenylate cyclase activity, there is a need for expanding the studies to include species and gestational ages that have not been examined to date.

\section{MATERIALS AND METHODS}

Materials. Drugs and reagents were obtained from commercial sources and were of reagent grade. $\left[\alpha-{ }^{32} \mathrm{P}\right] \mathrm{ATP}(10-30 \mathrm{Ci} / \mathrm{mmol})$, and $\left[3^{\prime}, 8^{\prime}-{ }^{3} \mathrm{H}\right] 3^{\prime}, 5^{\prime}$-cAMP $(15 \mathrm{Ci} / \mathrm{mmol})$ were obtained from ICN. 
Preparation of heart homogenates. Time-dated, pregnant New Zealand White rabbits were sacrificed at $21,25,28$, and 31 days gestation (term, 31 days). Intact hearts were removed from fetal rabbits and were either used fresh or immersed in liquid nitrogen and stored frozen at $-70^{\circ} \mathrm{C}$. No significant difference in enzymatic activity was noted between fresh and frozen tissue. On the day of the assay, the hearts were placed in 5 to 10 volumes/wet weight of ice-cold $0.9 \% \mathrm{NaCl}$ (wt/vol) and $20 \mathrm{mM}$ Tris-HCl (buffer A), pH 7.5. They were then minced with scissors and homogenized with a Brinkmann Polytron (setting 6-7, $10 \mathrm{~s}$ ). A crude membrane preparation was obtained from fetal hearts after centrifugation at $20,000 \times g$ for $10 \mathrm{~min}\left(4^{\circ} \mathrm{C}\right)(11)$. The pellets were then resuspended in $2 \mathrm{ml}$ of ice-cold buffer $\mathrm{A}$ and preincubated for $15 \mathrm{~min}$ at $30^{\circ} \mathrm{C}$ in the presence of $0.5 \mathrm{mM}$ dithiothreitol, $0.17 \mathrm{mM}$ EGTA, $1 \mathrm{mM} \mathrm{HCl}, 0.2 \%$ bovine serum albumin, $5 \mathrm{mM} \mathrm{MgCl}_{2}, \mathrm{pH} 7.45$. The suspension was then recentrifuged as previously outlined. The resulting pellets were resuspended in ice-cold buffer A (100-150 volumes/g wet weight) and used in the assay.

Adenylate cyclase assay. Adenylate cyclase activity was determined by measuring the conversion of $\left[\alpha-{ }^{32} \mathrm{P}\right] \mathrm{ATP}$ to $\left[{ }^{32} \mathrm{P}\right] \mathrm{cAMP}$ and isolating the product by a modification of a method developed by Salomon et al. (22). The reaction was carried out in duplicate or triplicate at $30^{\circ} \mathrm{C}$ for $10 \mathrm{~min}$ in a final volume of $0.2 \mathrm{ml}$ containing $0.1 \mathrm{ml}$ membrane fraction $(5-20 \mu \mathrm{g}$ of protein/ tube) and $50 \mathrm{mM}$ Tris- $\mathrm{HCl}, \mathrm{pH} 7.5,0.45 \% \mathrm{NaCl}, 0.5 \mathrm{mM}$ ATP, $5 \mathrm{mM} \mathrm{MgCl}_{2}, 0.17 \mathrm{mM}$ EGTA, $0.05 \mathrm{mM}$ cAMP, $0.5 \mathrm{mM}$ dithiothreitol, $0.75 \mathrm{mM}$ 3-isobutylmethylxanthine, $0.1 \mathrm{mg} / \mathrm{ml}$ creatine kinase, $10 \mathrm{mM}$ creatine phosphate, and $1-2 \times 10^{6} \mathrm{cpm}$ of $\left[\alpha-{ }^{32} \mathrm{P}\right]$ ATP. Appropriate drugs were added as required. The reaction was initiated by adding the membrane fraction to the incubation tubes. It was linear with respect to time $(20 \mathrm{~min})$ and protein concentration. The reaction was terminated by the addition of $0.25 \mathrm{ml}$ of a solution containing $50 \mathrm{mM}$ Tris- $\mathrm{HCl}(\mathrm{pH}$ 7.5), $5 \mathrm{mM}$ ATP, $1 \mathrm{mM}$ cAMP, and 5\% sodium dodecyl sulfate. $\left[{ }^{3} \mathrm{H}\right] \mathrm{cAMP}(10,000-15,000 \mathrm{cpm} /$ tube $)$ was added to all tubes to serve as an internal standard and monitor the efficiency of recovery. The tubes were then placed in boiling water for $10 \mathrm{~min}$ and then allowed to cool down to room temperature. $\left[{ }^{32} \mathrm{P}\right] \mathrm{cAMP}$ was isolated using sequential Dowex (AG 50W-X4, 200-400 mesh, Bio-Rad) and neutral alumina columns essentially as described by Salomon et al. (22) and counted in a scintillation counter (Tracor-III). Recovery of cyclic AMP was determined by per cent recovery of $\left[{ }^{3} \mathrm{H}\right]$ cAMP external standard in each sample.

Results have been corrected for per cent recovery (routinely greater than $60 \%$ ). Enzymatic activity was expressed as pmol $3^{\prime}, 5^{\prime}$-cAMP produced/mg of protein/min (per heart). $K_{\text {act }}$ values of the enzyme for $l$-isoproterenol (concentration of $l$-isoproterenol required to half-maximally stimulate enzymatic activity) was determined in some experiments by performing dose-response curves. $K_{\text {act }}$ was calculated by logit-log transformation of the data from each individual dose-response curve.

Protein assay. Protein concentrations were determined according to the method of Bradford using bovine serum albumin as a standard (4).

Statistical analysis. We utilized analysis of variance to test the null hypotheses that, with advancing gestation, there is no difference in maximal adenylate cyclase stimulation by agonists or $K_{\text {act }}$ of enzyme by $l$-isoproterenol. A $p$ value of less than 0.05 was considered significant. For multiple comparisons, analysis of variance with Scheffe's multiple range test was used.

\section{RESULTS}

In preliminary experiments, it was determined that basal adenylate cyclase activity at $21,25,28$, and 31 days gestation was only minimally increased in the presence of GTP or $l$-isoproterenol alone. However, when GTP was added in combination with $l$-isoproterenol, there was a substantial rise in the level of ade- nylate cyclase activity with maximal stimulation occurring at a GTP concentration of $100 \mu \mathrm{M}$. Thus, in order to effect equivalent comparisons between basal versus stimulated enzymatic activity, in all subsequently reported experiments, GTP was present in a final concentration of $100 \mu \mathrm{M}$. In contrast, NaF stimulation was not dependent on the presence of GTP.

Figure 1 shows basal adenylate cyclase activity in the presence of GTP and after stimulation by $\mathrm{NaF}$ and $l$-isoproterenol. The inhibition of $l$-isoproterenol stimulated enzymatic activity by $d l$ propranolol is also shown. Basal activity did not change significantly with advancing gestation. However, in all cases, there was a substantial increase in the enzymatic activity secondary to $\mathrm{NaF}$ stimulation. The per cent increase, compared to baseline, was not different in the gestational ages studied. In contrast, maximal stimulation by $l$-isoproterenol was significantly greater in the

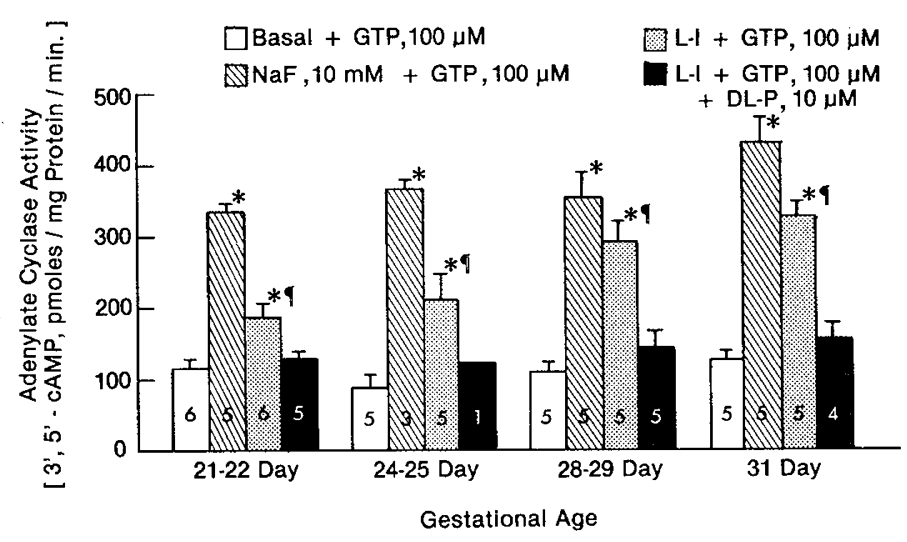

Fig. 1. Fetal rabbit myocardial adenylate cyclase activity from individual animals at different gestational ages. Data represent mean values \pm standard error from separate experiments performed in duplicate. Numbers within the bars indicate the number of individual animal hearts utilized for that determination. $L-I, l$-isoproterenol; $D L-P, d l$-propranolol. $* p<0.05$, for intragroup comparisons between basal and stimulated enzymatic activity ( $l$-isoproterenol and $\mathrm{NaF}$ ). $\uparrow p<0.05$ for intergroup comparisons between 21 - versus $25-, 28$, and 31 -day fetal rabbit hearts (basal versus $l$-isoproterenol-stimulated enzymatic activity).

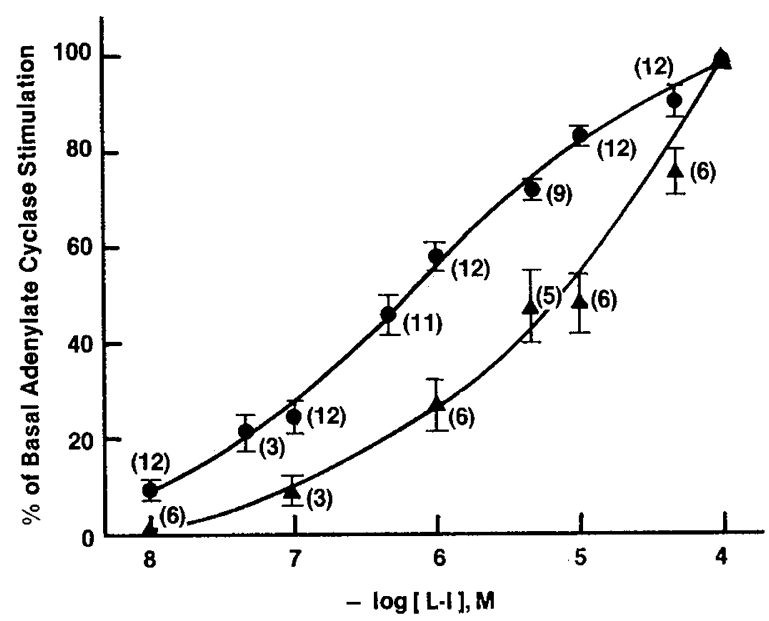

Fig. 2. Fetal rabbit myocardial adenylate cyclase activity as a function of $l$-isoproterenol concentration. Stimulated activity has been corrected for basal activity of adenylate cyclase. Data represent mean values \pm standard error from six (21-22-day pups, $\mathbf{\Delta})$ to 12 (25-31-day pups, separate experiments performed in duplicate. Numbers in parentheses indicate number of individual animal hearts used to determine enzymatic activity for a specific $l$-isoproterenol $(L-I)$ concentration. Maximal activity was measured in all myocardial membranes (six 21-22-day pups and twelve 25-31-day pups). 
Table 1. Adenylate cyclase stimulation, $K_{a c t}$ in fetal rabbit hearts

\begin{tabular}{crr}
\hline $\begin{array}{c}\text { Gestational } \\
\text { age (days) }\end{array}$ & $n$ & $K_{\text {act }}(\mu \mathrm{M})^{*}$ \\
\hline $21-22$ & 6 & $10.28 \pm 3.00 \dagger$ \\
$25-31$ & 12 & $0.85 \pm 0.17 \dagger$ \\
\hline
\end{tabular}

* Concentration of $l$-isoproterenol required to stimulate adenylate cyclase activity $50 \%$ above basal level, $\bar{x} \pm$ SEM.

$\dagger p<0.001$

25-, 28-, and 31-day gestation fetal myocardium than in the 21day fetuses. Finally, $l$-isoproterenol-stimulated adenylate cyclase activity was specifically inhibited by $d l$-propranolol in all groups tested.

The relationship of adenylate cyclase stimulation by increasing $l$-isoproterenol concentrations, in the presence of GTP, is shown in Figure 2. No significant differences were noted between 25-, 28-, and 31-day fetal hearts. However, there is a significant shift of the curve to the right when myocardial adenylate cyclase activity was studied in 21-day fetuses and compared to 25-31day fetuses. Using logit-log transformation of the data, $K_{\text {act }}$ of the enzyme was calculated. Table 1 shows the $K_{\text {act }}$ values determined individually in myocardial membranes from 21- and 2531 -day gestation fetuses. There is a highly significant decrease in the $K_{\text {act }}$ value with advancing gestation when data from 21 - and 25-31-day gestation fetuses are compared.

\section{DISCUSSION}

We have previously shown that there is a significant increase in $\beta$-adrenergic receptor concentration in fetal rabbit myocardial membranes from 21 to 31 days gestation. In contrast, the $K_{D}$ of these $\beta$-adrenergic receptors for ${ }^{125} \mathrm{I}$-HYP and their $K_{l}$ for $l$ isoproterenol did not show any developmental changes (11). Nor was there any change in our ability to detect a "high" and "low" affinity state of the receptor for $l$-isoproterenol in the absence or presence of GTP, respectively (12). We have now examined adenylate cyclase activity in similarly prepared fetal rabbit myocardial membranes from 21 to 31 days gestation, thus providing new information on the ontogenesis of $\beta$-adrenoreceptor/adenylate cyclase complex in this species.

Adenylate cyclase activity was detectable in fetal rabbit myocardial homogenates from single pups as early as 21 days gestation. This is the earliest time that this enzyme has been studied in this species. Basal enzymatic activity, in the presence of 100 $\mu \mathrm{M}$ GTP, did not change significantly with advancing gestation. Although the molecular explanation of basal adenylate cyclase activity is not well defined, it probably does not reflect the dynamic relationships between components of $\beta$-adrenoreceptor/adenylate cyclase complex and exogenous stimulators. For these reasons, we have extended our observations to include stimulation of enzymatic activity by a non- $\beta$-adrenoreceptordependent drug $(\mathrm{NaF})$ as well as a specific $\beta$-adrenoreceptor agonist, $l$-isoproterenol. We have found that $\mathrm{NaF}$-stimulated activity was similar in all gestational ages studied and was independent of GTP. This is consistent with previous observations concerning the probable mode of action of NaF mediated directly through another component of $\beta$-adrenoreceptor/adenylate cyclase complex, the so-called stimulatory nucleotide binding subunit (25). Since there was no significant difference in the degree of $\mathrm{NaF}$-dependent enzymatic stimulation with advancing gestation, it appears that the function of this component, as indicated by the degree of $\mathrm{NaF}$ stimulation, does not undergo any significant maturational changes.

In contrast to $\mathrm{NaF}, \beta$-adrenoreceptor-related adenylate cyclase activation is a GTP-dependent process in that l-isoproterenol required the presence of GTP in order to stimulate the enzyme. We showed that the extent of enzymatic stimulation by maximal concentrations of $l$-isoproterenol $(100 \mu \mathrm{M})$ was more marked in older (25-31-day gestation) than in the younger (21-day gestation) rabbit fetal hearts. Finally, the sensitivity of the enzyme to $l$-isoproterenol stimulation, as indicated by the decrease in $K_{\text {act }}$ values, increased substantially with advancing gestation (21versus 25-31-day gestation fetuses).

These results are somewhat in conflict with previously reported observations in neonatal rats and term fetal sheep as well as fetal rabbits $(3,6,23,30)$. It is conceivable that these contradictory findings may be attributed to different maturational profiles between species as well as the timing of tissue sampling (fetuses versus neonates, late gestation fetal sheep). An additional major point of difference between the previously reported rat (30) and rabbit (23) adenylate cyclase experiments and our studies is that they utilized pooled heart tissue from several animals of the same gestational or postnatal age while we studied individually prepared hearts. "Pooling" might have obscured intergroup as well as intragroup differences. Finally, the method of tissue preparation might have contributed to these discrepancies. In some adenylate cyclase studies, investigators have used either relatively crude myocardial membranes (8) or crude homogenates (19). Although a crude membrane preparation was used in our experiments, we tried to prepare heart membranes in a manner similar to that we reported in our $\beta$-adrenoreceptor studies $(11,12)$. This is an important consideration if $\beta$-adrenoreceptor properties are to be directly correlated with adenylate cyclase activity.

The developmental changes in per cent maximal adenylate cyclase stimulation by $l$-isoproterenol reported in this communication are consistent with our observations on the density of myocardial $\beta$-adrenoreceptors in this species (11). However, the observation that $K_{\text {act }}$ of the enzyme by $l$-isoproterenol decreases as the fetus approaches term suggests that there might be an increase in the sensitivity of the enzyme. The etiology for this latter change is not clear. However, it does not appear to involve an alteration in the interaction of fetal myocardial $\beta$-adrenoreceptors with $l$-isoproterenol in the presence of GTP (12). Further work in this area is warranted to elucidate the molecular stoichiometry of these changes.

Finally, these results on $\beta$-AR/adenylate cyclase maturation with advancing gestation, could, at least partially, account for the observed developmental changes in myocardial contractility and heart rate responses. It is noteworthy that the maturation of the $\beta$-AR/cyclase complex in this species occurs at a time that sympathetic neuronal input at the myocardial level is virtually nonexistent (9), implying that two components of the efferent limb of a sympathetic reflex arc develop independently of each other.

Acknowledgments. The author gratefully acknowledges Dr. Frank Greiss for his support and encouragement, Sandra Symmes for expert technical help, and Portia Ellerbe for help in preparation of this manuscript.

\section{REFERENCES}

1. Adolph EF 1971 Ontogeny of heart-rate controls in hamster, rat and guineapig. Am J Physiol 220:1896

2. Baker SP, Potter LT 1980 Cardiac $\beta$-adrenoreceptors during normal growth of male and female rats. Br J Pharmacol 68:65

3. Bhalla RC, Sharma RV, Ramanathan S 1980 Ontogenetic development of isoproterenol subsensitivity of myocardial adenylate cyclase and $\beta$-adrenergic receptors in spontaneously hypertensive rats. Biochim Biophys Acta 632:497

4. Bradford MM $1976 \mathrm{~A}$ rapid and sensitive method for the quantitation of microgram quantities of protein utilizing the principle of protein-dye binding. Anal Biochem 72:248

5. Chen FM, Yamamura HI, Roeske WR 1979 Ontogeny of mammalian myocardial $\beta$-adrenergic receptors. Eur J Pharmacol 58:255

6. Cheng JB, Goldfien A, Cornett LE, Roberts JM 1981 Identification of $\beta$ adrenergic receptors using ${ }^{3} \mathrm{H}$-dihydroalprenolol in fetal sheep heart: direct evidence of qualitative similarity to the receptors in adult sheep heart. Pediatr Res 15:1083

7. Clark JB, Vinicor F, Carr L, Clark CM 1980 Adenyl cyclase responsiveness to guanyl nucleotides in the developing rat heart. Pediatr Res 14:291

8. Davies AO, De Lean A, Lefkowitz RJ 1981 Myocardial beta-adrenergic receptors from adrenalectomized rats: impaired formation of high-affinity agonist- 
receptor complexes. Endocrinology 108:720

9. Friedman WF 1972 The intrinsic physiologic properties of the developing heart. Progr Cardiovasc Dis 15:84

10. Harris WH, Van Petten GR 1979 Development of cardiovascular responses to noradrenaline, adrenaline, normetanephrine, and metanephrine in the unanesthetized fetus. Can J Physiol Pharmacol 57:242

11. Hatjis CG, McLaughlin MK 1982 Identification and ontogenesis of betaadrenergic receptors in fetal and neonatal rabbit myocardium. J Dev Physiol $4: 327$

12. Hatjis CG $1984 \beta$-adrenergic receptor ( $\beta$-AR) interaction with guanine mucleotides $(\mathrm{GN})$ in fetal rabbit myocardial membranes. Biol Neonate, 46:254

13. Hegstrand LR, Minneman KP, Molinoff PB 1979 Multiple effects of guanosine triphosphate on beta adrenergic receptors and adenylate cyclase activity in rat heart, lung, and brain. J Pharmacol Exp Ther 210:215

14. Jones LR, Besch HR, Fleming JW, McConnaughey MM, Watanabe AM 1979 Separation of vesicles of cardiac sarcolemma from vesicles of cardiac sarcoplasmic reticulum. J Biol Chem 254:430

15. Kaumann AJ, Birnbaumer L 1974 Studies on receptor-mediated activation of adenylyl cyclases. J Biol Chem 249:7874

16. Kohrman AF 1973 Patterns of development of adenyl cyclase activity and norepinephrine responsiveness in the rat. Pediatr Res 7:575

17. Lands AM, Arnold A, McAuliff JP, Luduena FP, Brown TG 1967 Differentiation of receptor systems activated by sympathomimetric amines. Nature 214:597

18. Levy MN, Martin PJ 1979 Neural control of the heart. section 2. In Berne RM (ed) Handbook of Physiology, vol I, Sect 2. American Physiological Society, Bethesda, MD, p. 581

19. Minneman KP, Hegstrand LR, Molinoff PB 1979 The pharmacological specificity of beta- 1 and beta- 2 adrenergic receptors in rat heart and lung in vitro. Mol Pharmacol 16:21
20. Polson JB, Goldberg ND, Shideman FE 1977 Norepinephrine and isoproterenol induced changes in cardiac contractility and cyclic adenosine $3^{\prime}, 5^{\prime}$ monophosphate levels during early development of the embryonic chick. J Pharmacol Exp Ther 200:630

21. Rudolph AM, Heymann MA 1974 Fetal and neonatal circulation and respiration. Annu Rev Physiol 36:187

22. Salomon Y, Londos C, Rodbell M 1974 A highly sensitive adenylate cyclase assay. Anal Biochem 58:541

23. Schumacher WA Sheppard JR, Mirkin BL 1982 Biological maturation and beta-adrenergic effectors: pre- and postnatal development of the adenylate cyclase system in the rabbit heart. J Pharmacol Exp Ther 223:587

24. Snyder FF, Drummond GI 1978 Activation and stabilization of cardiac adenylate cyclase by GTP analog and fluoride. Arch Biochem Biophys 185:116

25. Spiegel AM, Downs RW Jr 1981 Guanine nucleotides: key regulators of hormone receptor-adenylate cyclase interaction. Endocrine Rev 2:275

26. Stull JT, Mayer SE 1979 Biochemical mechanisms of adrenergic and cholinergic regulation of myocardial contractility. In Berne RM (ed) Handbook of Physiology, vol l, sect 2. American Physiological Society, Bethesda, MD, p 581

27. Tse J, Powell JR, Baste CA, Priest RE, Kuo JF 1979 Isoproterenol-induced cardiac hypertrophy: modifications in characteristics of $\beta$-adrenergic receptor adenylate cyclase, and ventricular contraction. Endocrinology 105:246

28. Vapaavouri EK, Shinebourne EA, Williams RL, Heymann MA, Rudolph AM 1973 Development of cardiovascular responses to autonomic blockade in intact fetal and neonatal lambs. Biol Neonate 22:177

29. Ward RM Mirkin BL, Singh S, Daniels C 1981 Developmental increase in the cardiac chemotropic response to isoproterenol (IS). Pediatr Res 15:503

30. Whitsett JA, Darovec-Beckerman C 1981 Developmental aspects of $\beta$-adrenergic receptors and catecholamine-sensitive adenylate in rat myocardium. Pediatr Res 15:1363

\title{
Effects of Acidosis on Fetal and Maternal Blood Coagulation: A Fetal Lamb Model
}

\author{
C. THOMAS KISKER, DAVID P. BOHLKEN, AND WILLIAM R. CLARKE \\ Departments of Pediatrics and Preventive Medicine, University of Iowa College of Medicine, \\ Iowa City, Iowa 52242
}

\begin{abstract}
The effects of fetal acidosis (mean pH 6.93) on fetal and maternal blood coagulation were measured. Test results from 10 fetal lambs and mother ewes $(127 \pm$ 2 days mean gestation) before and after fetal lactic acid infusions were compared to test results from eight control fetal lambs and mother ewes (127 \pm 3 days mean gestation) before and after control glucose infusion. Significant changes found in acidotic fetal lambs not seen in control fetuses included an increase in the white blood cell count (mean $2800 / \mathrm{mm}^{3}$ before to $3600 / \mathrm{mm}^{3}$ after acidosis; $p=$ 0.0009 ), a shortening of the thrombin time (mean $17.8 \mathrm{~s}$ before to $11.2 \mathrm{~s}$ after acidosis; $p=0.0001$ ), and decreases in the activities of factor $\mathrm{V}$ (mean $57 \%$ before to $37 \%$ after acidosis; $p=0.0014$ ) and factor IX (mean $35 \%$ before to $29 \%$ after acidosis; $p=0.0128$ ). There was also a reduction in the concentration of fibrinogen (mean $147 \mathrm{mg} / 100 \mathrm{ml}$ before to $125 \mathrm{mg} / 100 \mathrm{ml}$ after acidosis; $p=0.0492$ ) but no significant changes in the levels of fibrin monomer, fibrin-
\end{abstract}

Received April 25, 1984; accepted July 27, 1984.

Address correspondence C. Thomas Kisker, M.D., Department of Pediatrics, University of lowa Hospitals and Clinics, Iowa City, IA 52242.

This research was supported by Grant R01 HD12574 from the National Institutes of Health. ogen/fibrin degradation products, or antithrombin III. In vitro exposure of five different fetal whole blood samples to a $\mathrm{pH}$ of 6.9 for $2 \mathrm{~h}$ at $37^{\circ} \mathrm{C}$ did not result in significant changes in any of the coagulation factor activities. A significant decrease in the level of factor $V$ was also found in the mother ewes of the acidotic fetuses (mean $141 \%$ before to $113 \%$ after acidosis; $p=0.006$ ) and a decrease in the level of maternal factor IX approached significance (mean $119 \%$ before to $102 \%$ after acidosis; $p=0.0564$ ). Two hours of severe fetal lactic acidosis induces changes in blood coagulation, but not the usual findings of disseminated intravascular coagulation. Corresponding decreases in factor $\mathrm{V}$ and $\mathrm{IX}$ activities in the mothers of acidotic fetal lambs suggest the liberation of a mediator capable of crossing the placenta and influencing maternal coagulation. (Pediatr Res 19: 78-82, 1985)

Significant acidosis is likely to occur in the fetus in association with placental infarction, cord compression, or partial abruption. Acidosis may also be present in association with hypoxia in 